\title{
Vibrating Mesh Nebulisers - Can Greater Drug Delivery to the Airways and Lungs Improve Respiratory Outcomes?
}

\author{
Stephan Ehrmann
}

Médecine Intensive Réanimation, Réseau CRICS-TRIGGERSEP, Centre Hospitalier Régional et Universitaire de Tours, INSERM U1100, Centre d'Études des Pathologies Respiratoires, Tours, France

A erosols are an increasingly important mode of delivery of drugs, particularly bronchodilators, for the treatment of respiratory diseases, notably asthma and chronic obstructive pulmonary disease. The most common type of nebuliser is the jet nebuliser (JN); they have been in use for more than a century but these devices can be cumbersome to use and may sometimes deliver insufficient amounts of drug. A more recent development in aerosol therapy is the vibrating mesh nebuliser (VMN) which is very user friendly and is more efficient than the JNs due to an extremely low residual volume. Scintigraphy images from studies of volunteer subjects using radio-labelled aerosol treatment show that VMN-generated aerosols deliver more drug to patients in a shorter period of time than JN-generated aerosols. Various bench, animal model and small clinical studies have shown that VMNs are more efficient than JNs in drug delivery, potentially improving clinical outcomes. These studies have included various breathing circuits used in mechanical ventilation (MV), non-invasive ventilation, high-flow nasal cannula systems and devices for spontaneously breathing patients. The efficiency of drug delivery was affected by factors including the position of the nebuliser in the circuit and humidity. Some studies have shown potential substantial savings by hospitals in the cost of MV treatments after switching from metered dose inhalers to VMNs. VMNs have also been shown to be effective for the administration of inhaled antibiotics, corticosteroids and other drugs. Larger studies of the effects of VMNs on patient outcomes are needed but they are likely to be an increasingly important means of administering therapies to a burgeoning population with respiratory disease.

\section{Keywords}

Vibrating mesh nebuliser, inhaled medication, respiratory disease, chronic obstructive pulmonary disease, asthma

Disclosure: Stephan Ehrmann has given presentations, acted as a consultant or received honoraria from: Aerogen, La Diffusion Technique Française, Fisher \& Paykel and Baxter.

Review Process: Double-blind peer review.

Acknowledgements: Medical writing support, including preparation of the drafts under the guidance of the author, was provided by James Gilbart of Touch Medical Media and funded by Aerogen.

Compliance with Ethics: This study involves a review of the literature and did not involve any studies with human or animal subject performed by the author.

Authorship: The named author meets the International Committee of Medical Journal Editors (ICMJE) criteria for authorship of this

manuscript, takes responsibility for the integrity of the work as a whole, and has given final approval for the version to be published.

open Access: This article is published under the Creative Commons Attribution Noncommercial License, which permits any non-commercia use, distribution, adaptation and reproduction provided the original author(s) and source are given appropriate credit. (c) The Author(s) 2018

Received: 3 November 2017

Accepted: 3 January 2018

Citation: European Respiratory \& Pulmonary Diseases. 2018;4(1):33-43

Corresponding Author: Stephan Ehrmann, Médecine Intensive Réanimation, Réseau CRICS-TRIGGERSEP, Centre Hospitalier Régional et Universitaire de Tours, INSERM U1100, Centre d'Études des Pathologies Respiratoires, Tours, France.

E: stephanehrmann@gmail.com Twitter: stephanehrmann

Support: The publication of this article was supported by Aerogen.

The views and opinions expressed in the article are those of

the author and not necessarily those of Aerogen.
Aerosol administration of drug therapies is a well-established and increasingly important delivery method for patients with acute or chronic respiratory conditions, especially for those receiving critical care. Aerosol therapies are now given to one-quarter of critically ill patients and one-fifth of ventilated patients, and they are widely used in chronic respiratory conditions, particularly chronic obstructive pulmonary disease (COPD) and asthma. ${ }^{1-5}$ Additionally, nebulisers are widely used for patients with cystic fibrosis (CF) in both hospital and home settings. ${ }^{6,7}$

A number of factors affect aerosol delivery including lung anatomy in relation to airway geometry and branching and narrowing of the airways. ${ }^{8}$ Mucociliary clearance mechanisms and humidity can also impede the inhalation of drugs. ${ }^{9}$ Additionally, factors associated with the type of ventilation, including tidal volume, inspiratory time and duty cycle, inspiratory flow, waveform and bias flow can affect aerosol deposition. ${ }^{10}$ The lung offers an attractive site for delivery as it has a large surface area and thin epithelium which permits rapid drug absorption. Drug delivery through the lung is also a non-invasive route for drug administration. ${ }^{9}$ When levels of drug absorption into the circulation are low, administration through inhalation is associated with fewer side effects than systemic administration. If, however, there is large and rapid absorption there can be more side effects. This painless delivery can provide a more rapid onset of action, have a higher therapeutic index and achieve higher pulmonary tissue concentrations than many systemically administered drugs. ${ }^{8}$ This is particularly important in the treatment of pulmonary infections.

Aerosols of drugs introduced to the breathing circuit need to be created efficiently with minimal drug wastage. The size of aerosol droplet should be consistent and small enough to facilitate airway penetration so that a high proportion of the dose is deposited into lung tissues. ${ }^{9,1,12}$ 
Jet nebulisers (JNS) have been used to administer drugs for around 150 years and are widely accepted. Aerosol droplet size for JNs, however, can be inconsistent and often there is incomplete nebulisation of the dose in the nebuliser reservoir. This results in variability of the actual dose delivered to the airways and lungs, which is a key factor affecting therapeutic response and is important when administering drugs such as antibiotics; for example, an imaging study reported that only $3 \%$ of the dose placed in the nebuliser actually reached the ventilated patient's lungs in the specific conditions studied..$^{13}$

The increasing prevalence of COPD and asthma is creating substantial healthcare burdens and is diminishing quality-of-life worldwide. ${ }^{14-17}$ These diseases impose high treatment costs where escalation of hospital care is required and there are consequent economic effects resulting from disability and incapacity. ${ }^{17-22}$ The World Health Organisation (WHO) estimates that 65 million people have COPD and believe it to be the current fifth leading cause of death, expecting it to rise to the third leading cause by $2030 .{ }^{23}$ Asthma exerts a significant burden in all territories in all age groups; it is estimated to affect between 235 and 334 million people worldwide and this prevalence is rising. ${ }^{24,25}$ Although the prevalence of $\mathrm{CF}$ is much lower, the associated lung disease requires chronic treatment which places a serious burden on patients, carers and healthcare systems. Treatments for COPD, asthma and CF during acute disease exacerbations are therefore of critical importance.

Efficient nebulisers and inhalers have the potential to improve cost effectiveness of treatments through shorter treatments and reduced drug wastage.26-29 Newer high-performance aerosol delivery such as vibrating mesh nebulisers (VMNs) are a vital means of rapidly administering medications such as bronchodilators, steroids and antibiotics. These maximise drug delivery with low residual volumes and some early data suggest that they may improve clinical outcomes more than other, less efficient aerosol generators. ${ }^{30,31}$ Early retrospective data support this and also suggest that efficient nebulisers and inhalers may reduce hospital admission rates and reduce the drug dosage needed for patients requiring bronchodilators in emergency departments. This results in improved patient throughput in busy acute care settings. The use of such treatments has the potential to rapidly improve a patient's condition and may improve long-term outcomes. 5,12,32,33

This review examines the evidence supporting the use of VMN devices and their current and potential roles in delivering drug therapy to patients with respiratory disease.

\section{The vibrating mesh nebuliser}

The VMN consists of recently developed aerosol technology that improves the delivery of aerosolised drugs to the lungs. The device has a very different design to conventional jet nebulisers. The key component is a central aperture plate that is perforated with precisely formed holes. A piezo ring vibrates the aperture plate which acts as a micro-pump drawing liquid through the holes to generate consistently sized fine particles of $1-5 \mu \mathrm{m}$ diameter. ${ }^{12,34}$ This size of particle is advantageous because particles of 5-10 $\mu \mathrm{m}$ diameter will not penetrate beyond the larger lung airways. ${ }^{35}$

VMNs produce a low velocity aerosol which minimises 'rainout' (condensation of drug-containing solutions) in the circuit and upper airways thereby optimising drug deposition. They generate no heat and so maintain drug integrity.3.,36,37 Several different VMN systems are

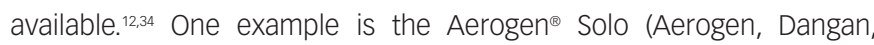
Galway, Ireland), which can be used during mechanical ventilation
(MV), non-invasive ventilation (NIV) and high-flow oxygen nasal cannula ventilation (HFNC); its utility has been demonstrated in various clinical studies. ${ }^{30,31,38-41}$ Other VMN devices include the NEBU-TEC ${ }^{\oplus}$ M-neb ${ }^{\circledR}$ (NEBU-TEC International med. Produkte Eike Kern GmbH, Elsenfeld, Germany), which is also used in MV but there is currently little information supporting its clinical use. VMN technology is also successfully used to generate aerosols in handheld nebuliser devices such as the PARI eFlow (PARI Medical Limited, West Byfleet, Surrey, UK) and the Aerogen ${ }^{\circledast}$ Ultra (Aerogen, Dangan, Galway, Ireland) (Table 1). ${ }^{42-45}$

VMNs have a number of further advantages over JNs especially when used with MV systems. Some VMNs can remain in the circuit for up to 28 days with no influence on the gas flow when delivering nebulised drugs. ${ }^{146,47}$ VMNs do not alter air flows or pressures in the circuit and require less frequent intervention from medical staff.,147 JNs require switching in and out of an MV circuit every 24 hours, which can be time consuming. Such processes can also be hazardous since there is a risk of lung derecruitment in sicker patients, after which re-establishing airflows can take time and opening the circuit can create opportunities for introducing infection leading to pneumonia. ${ }^{48}$ Reduced need for intervention from nursing staff and reduced infection risk have the potential to reduce costs of treating patients on $\mathrm{MV}^{49}$ Delivery of some viscous drugs, suspensions and solutions prone to crystallisation on drying can sometimes clog the pores of VMNs. This can usually be avoided by nebulising a few drops of normal saline at the end of the nebulisation period to clear the pores. There is also some variability in VMN output and nebulisation times, but this has limited practical impact in the hospital setting. In spontaneous breathers there is a requirement to disassemble the VMN from its valved adapter to allow it to air dry between uses. Although more efficient, VMNs are generally more expensive than JNS, but in the intensive care unit (ICU) setting a VMN can be used for up to 28 days in a single patient.

Another type of aerosol generator is the ultrasonic nebuliser (UN). These were first developed in the 1960s and are also used to treat airway diseases. These nebulisers have a piezoelectric crystal that vibrates at high frequencies (1-3 MHz) in a liquid to form an aerosol. ${ }^{50}$ These devices are small, easy to use, require no air compressor, have quiet operation and, like VMNs, are more efficient aerosol generators than the JNs. UNS are mostly used for the administration of hypertonic saline but can also be used for the delivery of inhaled medications. ${ }^{51}$ The main disadvantage of UNs is that heat is generated in the process of producing aerosol; this can break down complex proteins in some inhaled medications. In addition, UNs are not recommended for administration of suspensions such as Pulmicort ${ }^{\circledR}$ (budesonide). ${ }^{1}$ They are therefore unsuitable for administration of suspensions and proteins. They are also unable to create aerosols from viscous solutions and have a large residual volume. Both UNS and VMNs have controllers that drive them, but the UN's controller is bulkier and heavier. The UN has a reservoir that is positioned below the ventilator circuit whereby contaminated fluids in the circuit can more readily enter the nebulizer.' Some comparative in vitro studies have shown that UNs have a fast delivery but can have poorer efficiency and produce larger particles than VMNs. ${ }^{29,50,52,53}$

\section{Vibrating mesh nebulisers used with mechanical ventilation}

MV is used for the most seriously ill and critical patients, but more recently there has been a general trend towards less invasive means of ventilatory support for many such patients. ${ }^{54-56}$ Aerosol therapy is frequently introduced into mechanical breathing circuits and is used by over $95 \%$ of intensivists, mostly for bronchodilator, antibiotic and steroid 
Table 1: Vibrating mesh nebuliser systems currently available

\begin{tabular}{|c|c|c|c|c|}
\hline Nebuliser system & $\begin{array}{l}\text { Use as a } \\
\text { portable } \\
\text { handheld } \\
\text { device }\end{array}$ & $\begin{array}{l}\text { Use in } \\
\text { breathing } \\
\text { circuits for } \\
\text { mechanical } \\
\text { ventilation }\end{array}$ & Device & Advantages and use in studies \\
\hline $\begin{array}{l}\text { Omron }^{\oplus} \text { Micro Air } \\
\text { Nebulizer NE-U22V } \\
\text { (and NE-U03): } \\
\text { battery-operated }{ }^{42}\end{array}$ & + & - & & $\begin{array}{l}\text { A small-sized nebuliser, with quiet operation and tubeless and cordless } \\
\text { design. A piezoelectric crystal vibrates at a high frequency when an electrical } \\
\text { current is applied. Efficient aerosol delivery with fine particle fraction produces } \\
\text { a low velocity aerosol. The device has a low residual volume and delivers most } \\
\text { medications. No diluent is needed. }\end{array}$ \\
\hline $\begin{array}{l}\text { PARI eFlow rapid nebulizer } \\
\text { system: small, portable, } \\
\text { battery-operated device } \\
\text { with silent operation }{ }^{43}\end{array}$ & + & - & & $\begin{array}{l}\text { A highly-efficient nebuliser producing aerosols with a high fine particle fraction. } \\
\text { Patient compliance is improved due to the short treatment time. The device } \\
\text { is powered by battery or external electrical supply, and is controlled using an } \\
\text { external controller. The device is quiet while running, suitable for the delivery of } \\
\text { most medications, easy to clean and can be disinfected or autoclaved. }\end{array}$ \\
\hline Aerogen ${ }^{\circledast}$ Solo $^{44}$ & - & + & & $\begin{array}{l}\text { The Aerogen Solo has a piezo ring that vibrates the aperture plate at a rate } \\
\text { of } 128,000 \text { per second. Each aperture acts as a micro pump, drawing liquid } \\
\text { through a cone-shaped hole resulting in up to } 7.7 \text { billion precise, consistently } \\
\text { sized fine particles of } 1-5 \mu \text { m every minute. Particles sized } 5-10 \mu \mathrm{m} \text { will } \\
\text { not penetrate beyond the larger lung airways. The nebuliser operates with } \\
\text { ventilated and non-ventilated patients (coupled with the Aerogen }{ }^{\circledR} \text { Ultra; see } \\
\text { below). The device is economical and a single patient can use Aerogen Solo } \\
\text { for up to } 28 \text { days. It does not heat or degrade medication and so is suitable for } \\
\text { solutions, suspensions, proteins and peptides. The device has a low residual } \\
\text { volume. Aerogen Solo is currently the only standalone, single-patient mesh } \\
\text { device commercially available for use in mechanically ventilated patients. It } \\
\text { is powered by an external controller for } 30-\text {-minute or 6-hour durations, or for } \\
\text { continuous use. }\end{array}$ \\
\hline Aerogen ${ }^{\circledast}$ Ultra $^{45}$ & + & - & & $\begin{array}{l}\text { Aerogen Ultra is a valved holding chamber for use with Aerogen Solo } \\
\text { in patients with spontaneous breathing. It has an ergonomic valved } \\
\text { mouthpiece controlling air flow, maximising aerosol delivery. It can be used } \\
\text { with standard or valved face masks. Supplementary oxygen can be delivered } \\
\text { with the aerosol. }\end{array}$ \\
\hline
\end{tabular}

administration, $51,57-59$ and less frequently for anticoagulants, diuretics, mucoactive agents, prostacyclins and surfactants. ${ }^{46}$

One recent in vitro study compared the performance of four different nebulisers; the SideStream ${ }^{\circledR}$ Disposable JN (Philips Healthcare Limited, Guildford, Surrey, UK), the Multisonic ${ }^{\circledR}$ InfraControl UN (Flores medical GmbH, Probstzella, Germany), the Aerogen ${ }^{\circledR}$ Pro VMN and the Aerogen ${ }^{\circledR}$ Solo VMN (Aerogen, Dangan, Galway, Ireland) to deliver salbutamol in a model MV system. ${ }^{52}$ The UN was the fastest system to nebulise the dose; the JN was the slowest. Solution temperatures increased with the $\mathrm{JN}$ and UN, but decreased with the VMNs. Osmolarity increased with the JN and UN, but was stable with the VMNs. Salbutamol delivery was 2.3- and 1.6-fold higher with the VMNS and UN, respectively, compared with the JN. In addition, particle size was significantly greater with the UN (mean mass distribution: JN: $5.00 \pm 0.36 \mu \mathrm{m}, \mathrm{UN}$ : $5.80 \pm 0.07 \mu \mathrm{m}$, VMNs: $5.14 \pm 0.54 \mu \mathrm{m}$ (Aerogen Pro) and $4.60 \pm 0.54 \mu \mathrm{m}$ (Aerogen Solo); $p<0.01$ for UN versus VMN (Aerogen Pro). Overall, the VMNs and the UN were more efficient than the $\mathrm{JN}$, but the VMNs did not heat the drug and produced a substantially higher respirable fraction.

Several bench and imaging studies have demonstrated suitability of VMN technology for use in MV circuits and improved drug delivery of aerosolised solutions. .2,60-63 $^{2,6 e s e}$ investigations generally showed that aerosol devices are more efficient when placed at the ventilator or humidifier and less efficient at or near the Y-piece when bias flow was present (Figure 1). ${ }^{61}$
Figure 1: Comparison of salbutamol levels captured at the end of an endotracheal tube using a model ventilator circuit with four different nebuliser systems at two different positions (ventilator column or Y-piece before humidifier)

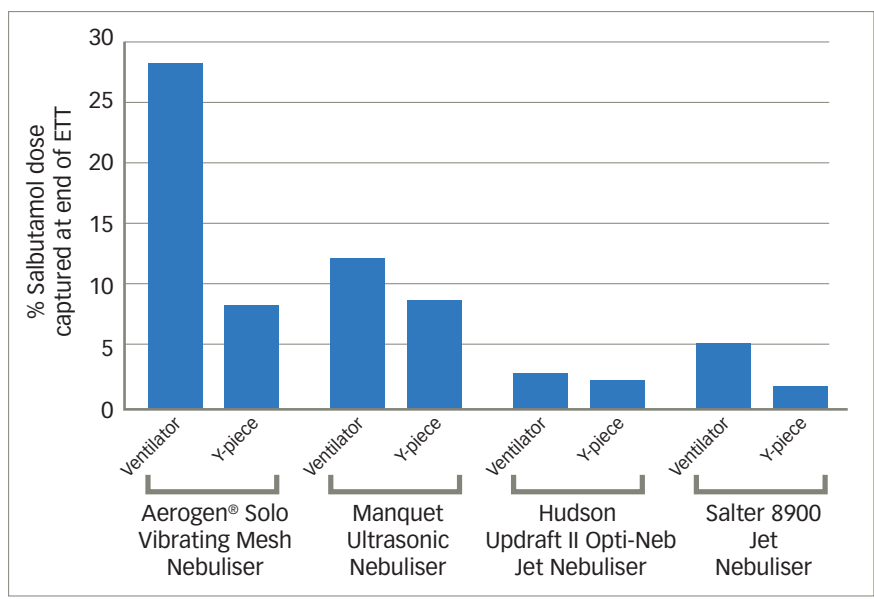

Total dose of salbutamol was $2.5 \mathrm{mg}$ in each case. ETT = endotracheal tube. Modified with permission from Berlinski and Willis, 2013.61

Berlinski and Willis showed that a VMN delivers ninefold more aerosol dose compared with a JN during simulated mechanical ventilation. ${ }^{61} \mathrm{~A}$ further bench study using both paediatric and adult breathing model systems showed that nebuliser placement prior to the humidifier 
Figure 2: Vibrating mesh nebuliser aerosols delivered via pressure support ventilation and volume-controlled ventilation A: Penetration index; B: Right/left lung deposition ratio. C: Scintigraphic images of aerosol lung deposition

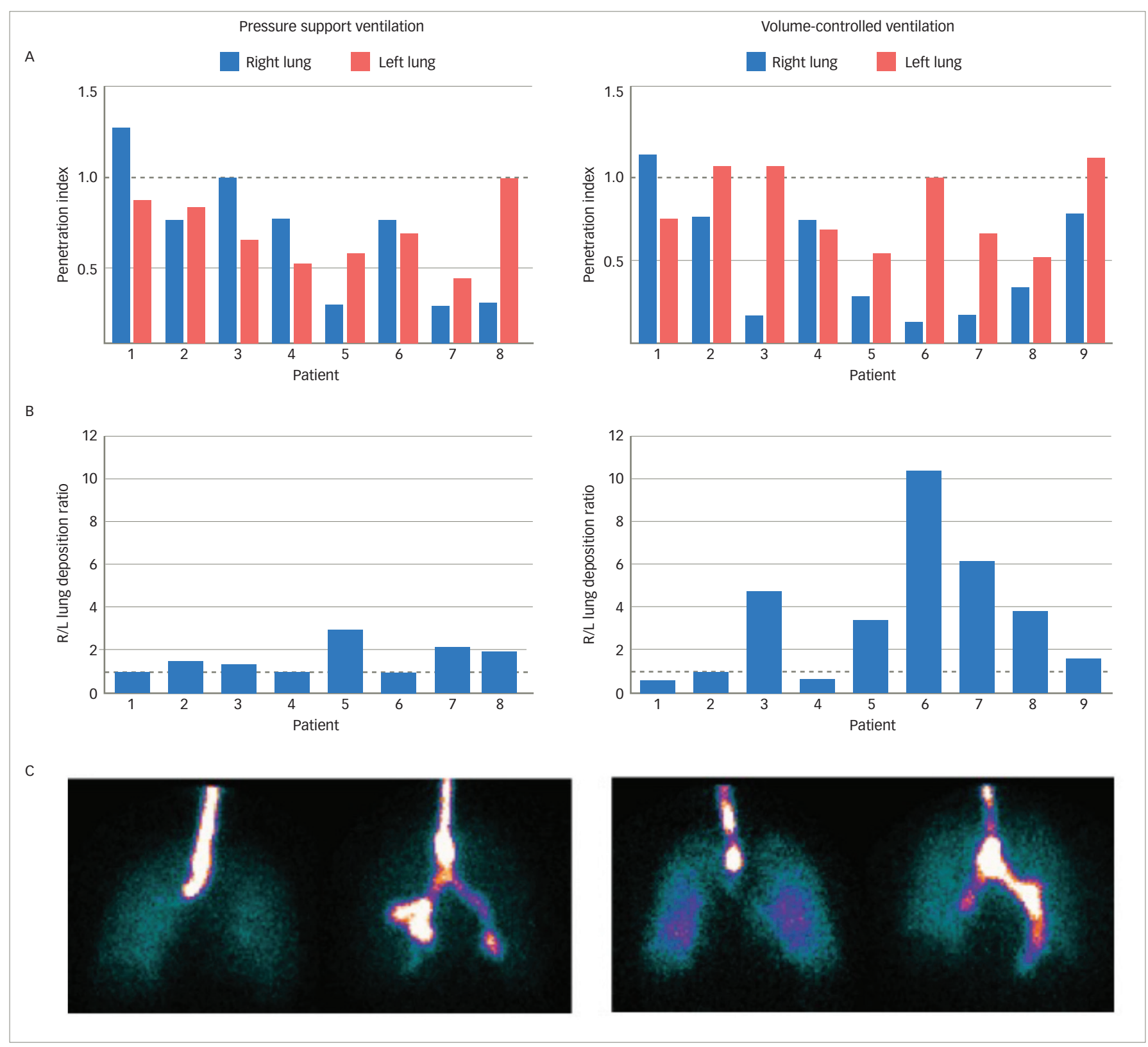

Reproduced with permission from Dugernier et al., 2016.39

increased drug delivery to a greater extent with a VMN than with a JN and that higher bias flow reduced drug delivery. ${ }^{64}$ In both model systems drug delivery with the VMN was two- to fourfold greater than with the JN at all positions $(p<0.05)$.

A randomised, controlled study compared the in vivo impact of two ventilation modalities - pressure support versus volume-controlled ventilation - on lung dose of a radiolabelled aerosol administered with a VMN during invasive mechanical ventilation and was measured using scintigraphy. ${ }^{39}$ The study enrolled postoperative neurosurgery patients who were mechanically ventilated with healthy lung function and found that controlling the ventilatory pattern in volume control mode was associated with higher lung deposition compared with spontaneous ventilation in pressure support mode (15.1\% versus $10.5 \%$; $p<0.05)$ (Figure 2). These levels of deposition are considerably higher than the deposition of 3.0\% observed with standard JNS..$^{13}$ Lung dose and the site of deposition were highly variable among patients with both ventilation modes.
The performance of VMNs have also been demonstrated in animal models. One example used a macaque model of a neonate and compared a JN (Misty-Neb [CareFusion, San Diego, CA, US]) with a VMN (Aerogen Pro [Aerogen, Dangan, Galway, Ireland]). This study used scintigraphy to demonstrate that $0.5 \%$ and $12.6 \%$ of ${ }^{99 m} \mathrm{TC}$-diethylenetriamine pentaacetic acid (DTPA) was delivered to the lungs using the JN and VMN, resepectively.6. This and other studies indicated that the advantages of VMN are mainly driven through lower residual volumes.

Early clinical data suggest that the higher drug deposition associated with VMNs can improve pulmonary mechanics. One study included 25 children (aged 1-18 years) with respiratory failure (the majority had postoperative respiratory failure with pulmonary oedema) who were treated with salbutamol delivered by VMN. ${ }^{66}$ At baseline, functional residual capacity was only $53.0 \%$ of that predicted. After aerosolised salbutamol, functional residual capacity increased by $18.3 \%$ ( $p=0.008)$. The authors concluded that in infants and children, salbutamol 
Table 2: Cost effectiveness studies conducted in the United States comparing vibrating mesh nebulisers with metered dose inhalers in mechanically ventilated patients

\begin{tabular}{|c|c|c|c|}
\hline Study reference and design & Comparison & Cost savings & Other effects \\
\hline $\begin{array}{l}\text { Retrospective study of patients } \\
\text { receiving MV in one US hospital }{ }^{68}\end{array}$ & $\begin{array}{l}\text { Cost of pMDI (1-year period) switched to } \\
\text { VMN (Aerogen Solo; 1-year period) for } \\
\text { bronchodilator administration in patients } \\
\text { receiving MV over } 2 \text { consecutive years }\end{array}$ & $\begin{array}{l}\text { Net cost savings of } \$ 208,828 \\
\text { with VMN }\end{array}$ & $\begin{array}{l}\text { Patients were considered to respond more } \\
\text { favourably with a VMN, but had more } \\
\text { medication side effects, possibly due to } \\
\text { greater exposure to medication }\end{array}$ \\
\hline $\begin{array}{l}\text { Retrospective study in one US } \\
\text { hospital (1,242 beds) using EHR } \\
\text { data }^{69}\end{array}$ & $\begin{array}{l}\text { Financial impact of MDI conversion to } \\
\text { VMN (Aerogen Solo) for bronchodilator } \\
\text { administration in patients receiving MV } \\
\text { during 3-month periods before and } \\
\text { after switching }\end{array}$ & $\begin{array}{l}\text { Extrapolated total cost saving } \\
\text { of } \$ 146,806 \text { in the first year and } \\
\$ 257,963 \text { in subsequent years } \\
\text { with VMN }\end{array}$ & $\begin{array}{l}\text { No difference in end-user satisfaction, } \\
\text { ventilator days, length of stay or rates of } \\
\text { ventilator-acquired pneumonia }\end{array}$ \\
\hline $\begin{array}{l}\text { Survey of } 13 \text { high-utilisation US } \\
\text { hospitals }^{45}\end{array}$ & $\begin{array}{l}\text { Cost savings on switching from pMDIs } \\
\text { to VMN (Aerogen Solo) for delivery of } \\
\text { bronchodilator drugs to patients in acute } \\
\text { care receiving MV over a 6-month period }\end{array}$ & $\begin{array}{l}\text { Pharmacy savings of } \$ 226,000 \\
\text { (3.4\% of total drug costs) } \\
\text { with VMNs }\end{array}$ & $\begin{array}{l}\text { Among respiratory therapists, } 69 \% \text { were } \\
\text { very satisfied with the VMN; } 83 \% \text { chose } \\
\text { VMN over JNs or pMDIs as the best aerosol } \\
\text { delivery method }\end{array}$ \\
\hline $\begin{array}{l}\text { Survey of a US hospital (part of a } \\
105 \text { hospital system) }\end{array}$ & $\begin{array}{l}\text { Financial impact of transition from MDI to } \\
\text { VMNs (Aerogen) in patients receiving MV } \\
\text { (1 year receiving each type) }\end{array}$ & $\begin{array}{l}\text { Saving per patient after transition } \\
\text { to VMNs of } \$ 145 \text {. Potential } \\
\text { system-wide annual cost savings } \\
\text { of } \$ 1,740,000\end{array}$ & $\begin{array}{l}\text { Respiratory staff satisfaction; process } \\
\text { changes can be implemented at other } \\
\text { hospitals, initiated by the multidisciplinary } \\
\text { team; no additional pressure in circuit; } \\
\text { ventilator checks can be performed } \\
\text { during administration }\end{array}$ \\
\hline
\end{tabular}

EHR = electronic health records; $J N=$ jet nebuliser; $M V=$ mechanical ventilation; $p M D I=$ pressurised metered dose inhaler; VMN = vibrating mesh nebuliser.

aerosolised by VMN might favourably enhance pulmonary mechanics and thereby represent a novel strategy for lung recruitment in children with respiratory failure.

Several studies in the US have demonstrated substantial cost savings when switching from pressurised metered dose inhaler (pMDI) to VMN administration of drug treatments during MV. This effect is partly due to the relatively higher costs of pMDIs in the US. ${ }^{67}$ In these studies, switching from pMDIs to VMNs resulted in projected cost savings of approximately $\$ 150,000$ to over $\$ 1.7$ million per year depending on the numbers of hospitals involved. In some of these studies, the savings were made in parallel with improved patient and/or medical staff satisfaction over

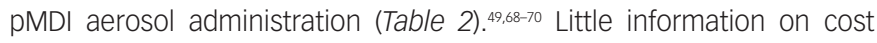
savings associated with VMN use with mechanical or other ventilator types in Europe is currently available.

Lung infections are a serious risk in patients with respiratory disease, particularly in those receiving $\mathrm{MV}$, and they can be difficult to treat. VMNs in combination with MV have been successfully used to deliver antibiotic aerosol treatments directly to the lung in several studies. In one study of 165 patients with ventilator-acquired pneumonia (VAP), treatment with aerosolised colistin from a VMN (Aerogen Pro). achieved cure rates of $66 \%$ in patients with antibiotic-sensitive Pseudomonas aeruginosa or Acinetobacter baumannii infections and $67 \%$ with multidrug resistant infections of these bacteria.. ${ }^{17}$ This efficacy was noninferior to intravenous treatments with $\beta$-lactams, aminoglycosides or quinolones for treating VAP. A similar study that included 149 critically ill adults found that VMN-aerosolised colistin achieved a clinical cure rate of $67.1 \%$ in P. aeruginosa and A. baumannii infections compared with $72.0 \%$ receiving intravenous colistin $(p=0.59) .{ }^{72}$ The aerosol-treated patients also had significantly lower incidence of acute renal failure $(p=0.004)$, shorter time to bacterial eradication ( $p=0.023$ ) and earlier weaning from the ventilator (gain of 5 ventilator-free days). In an international survey of aerosol therapies administered during mechanical ventilation, ${ }^{51} 80 \%$ of 854 analysed responses had a positive opinion of nebulised colistin and $30 \%$ reported using nebulised antibiotics at least every other month.

\section{Vibrating mesh nebulisers used with non-invasive ventilation}

Non-invasive ventilation (NIV) is increasingly used as a less invasive option when MV can be avoided. NIV can be associated with lower morbidity than MV and reduces the risk of VAP. ${ }^{73-75}$ Some patients with severe COPD receive intermittent NIV in the homecare setting. ${ }^{76,77}$ A variety of bench studies have demonstrated the use of VMNs during NIV using simulated breathing patterns. ${ }^{78-81}$ One such NIV model compared terbutaline aerosol generated by VMN and a JN. The VMN produced aerosols that contained significantly more drug than the $\mathrm{JN}$ and this difference was more marked when the nebuliser was positioned before the leak port in the ventilation circuit $(p<0.001$ for $V M N$ versus $J N$ and $p<0.001$ for position comparison)..$^{78}$ Another bench study using a face model/respiration simulator showed that the proportion of drug (99mTC-salbutamol) inhaled via aerosol using a VMN was substantially greater than with a JN for three different NIV settings (VMN: 14.3-15.4\% versus JN: 3.6-7.2\%; $p=0.004-0.094) .79 \mathrm{~A}$ comparison of a VMN, JN and PMDI used in an NIV model showed that the VMN was superior in terms of salbutamol delivery $(p<0.001)$ and that placing each nebuliser before the leak port provided the best drug delivery $(p<0.001){ }^{81}$

An NIV in vitro study compared the performance of three VMNS (Aerogen Pro, Aerogen Solo, and NIVO ${ }^{\circledR}$ [Philips UK Ltd, Guildford, Surrey, UK]), one JN (Sidestream), and one UN (Servo Ultra Nebulizer 145 [Siemens-Elema AB, Solna, Sweden]) coupled with a single-limb bilevel ventilator in the delivery of amikacin. ${ }^{29}$ When the nebuliser was positioned before the exhalation port in the circuit, the VMN delivered the highest inhaled dose $(p<0.001)$, the $J N$ showed the highest expiratory wasted dose $(p<0.001)$ and UN had the highest total lost dose $(p<0.001)$. When the nebulisers were placed after the exhalation port, however, the VMN showed the highest expiratory wasted dose. The authors concluded that UNS are not recommended in this NIV application and that the VMNs were the most efficient provided they were placed before the exhalation port. 
Clinical evidence supporting the use of VMNs with NIV in respiratory disease is, as yet, limited. In a crossover study, 10 healthy volunteers received ${ }^{99 m}$ TC-DTPA aerosol treatment via VMN or JN connected to an NIV circuit using a facemask. Radioactive counts and scintigraphy images showed that healthy subjects received greater than threefold more radioactive drug during $\mathrm{VMN}$ treatment than during JN treatment. ${ }^{82}$ This evidence indicates that there is potential for VMN devices to be used in combination with NIV as successfully as with other ventilation approaches, but larger comparative trials are needed.

\section{Vibrating mesh nebulisers used with high-flow oxygen through nasal cannulas}

Therapy with high-flow oxygen through nasal cannulas may offer an alternative to MV and NIV in some patients. A number of different bench studies have demonstrated VMN aerosol medication delivery via HFNCS and explored the optimal position of the nebuliser in the circuit. ${ }^{11,83-86}$ A model HFNC system with a VMN placed on the patient side of a humidifier found that cannula output ranged from $8.45-26.90 \%$ of the loaded dose depending on the variable flow rates. ${ }^{11}$ The median particle sizes generated were $4.2 \pm 0.4 \mu \mathrm{m}$ for adult cannulas and $3.8 \pm 0.5 \mu \mathrm{m}$ for paediatric cannulas. A study with a model paediatric breathing circuit showed that when using a VMN with a HFNC, decreasing the flow of oxygen or heliox (helium and oxygen) from $6 \mathrm{~L} / \mathrm{min}$ to $3 \mathrm{~L} / \mathrm{min}$ increased salbutamol lung deposition delivery twofold or greater ( $\mathrm{p}=0.028$ and 0.002 , respectively). ${ }^{.3}$ At $6 \mathrm{~L} / \mathrm{min}$ drug deposition was twofold or greater with heliox than with oxygen $(p=0.01)$. A further in vitro study using three different HFNC systems found that a $10 \mathrm{~L} / \mathrm{min}$ air flow provided the best drug delivery. ${ }^{84}$ At $30 \mathrm{~L} / \mathrm{min}$ and $50 \mathrm{~L} / \mathrm{min}$ the size of the cannula made a significant difference $(p<0.001)$. A study modelling HFNC with a VMN or JN in adults showed similar findings in that more drug (salbutamol) was delivered to the lungs with an air flow of $30 \mathrm{~L} / \mathrm{min}$ rather than $45 \mathrm{~L} / \mathrm{min}$ or $60 \mathrm{~L} / \mathrm{min}$. This delivery was not affected by high inspiratory flows as would be seen during respiratory distress. ${ }^{85}$ This study also found that the most efficient position of the nebuliser was before the humidifier allowing greater drug delivery beyond the nose and pharynx.

Despite the improved efficiency of VMNs compared with JNs used in HFNC, the total proportion of drug nebulised with HFNC is lower than with other ventilator methods. A recent scintigraphy study included six healthy subjects and compared lung deposition using ${ }^{99 m}$ TC-DTPA ( $4 \mathrm{mCi} / 4 \mathrm{ml}$ ) administered via a VMN (Aerogen Solo) or a JN (Opti-Mist Plus [ConvaTec Limited, Deeside, Flintshire, UK]) via an HFNC (Optiflow TM [Fisher \& Paykel Healthcare Limited, Auckland, New Zealand]). ${ }^{38}$ In the specific conditions of the study, with a flow rate of $30 \mathrm{~L} / \mathrm{min}$, lung deposition was $3.6 \%$ of the nominal dose with the VMN compared with $1.0 \%$ for the JN. Both nebulisers were associated with substantial deposition in the single limb circuit, the humidification chamber and the nasal cannula (58.2\% versus $19.2 \% ; p<0.05$ ) and in the upper respiratory tract, especially in the nasal cavity $(17.6 \%$ versus $8.6 \%$; $p<0.05)$.

A further study of VMN used in a HFNC system in 23 healthy adult volunteers confirmed effective delivery of ${ }^{99 m}$ TC-DTPA. ${ }^{87}$ Scintigraphy images showed the greatest deposition occurred at $10 \mathrm{~L} / \mathrm{min}$ compared with $30 \mathrm{~L} / \mathrm{min}$ or $50 \mathrm{~L} / \mathrm{min}$, and that there was a strong inverse correlation between lung deposition and air flow in both heated and unheated conditions $\left(r^{2}=-0.008\right.$ and -0.597 , respectively). Overall, aerosol administration via HFNC was seen to be a viable option for delivering clinically relevant doses to the lung. It should be stressed that in the acute setting, physicians use more than $50 \mathrm{~L} / \mathrm{min}$ or $60 \mathrm{~L} / \mathrm{min}$ to provide positive pressure and increase oxygen saturation levels to adult patients. In some cases, however, it may be necessary to decrease flow to deliver a meaningful dose of bronchodilator in severe bronchospasm; with VMNs the duration of nebulisation is shorter than with JNs keeping times of lower flow to a minimum.

In an interim analysis of an ongoing, randomised, crossover clinical study, 13 adult patients with respiratory failure received a nebulised bronchodilator via a VMN through HFNC, via a standard JN and facemask or just HFNC with sham nebulisation (no drug). HFNC was operated with a low airflow of $30 \mathrm{~L} / \mathrm{min} .{ }^{41}$ The absolute and relative changes in forced expiratory volume in one second $\left(\mathrm{FEV}_{1}\right)$ were: for HFNC/VMN: $330 \mathrm{ml},+17 \%$; for standard facemask/JN: $350 \mathrm{ml},+18 \%$ and for HFNC and sham nebulisation: $40 \mathrm{ml},+2 \%$. This interim analysis suggests that at $30 \mathrm{~L} / \mathrm{min}$ airflow, the HFNC/VMN treatment was noninferior to standard facemask/JN treatment and that both were greatly superior to HFNC with sham treatment.

Additional evidence supporting the use of VMNs with HFNC was provided by a case series of five infants with asthma and bronchiolitis due to rhinovirus or enterovirus infection who were initially treated with bronchodilators via JN and standard facemask, and then switched to HFNC with VMN.8 ${ }^{83}$ Following treatment with HFNC and VMN the infants became markedly less agitated than with the JN and facemask, suggesting that HFNC with VMN was clinically better tolerated, possibly preventing them from escalating to more invasive respiratory support. Mean heart rate was also substantially higher at 187 beats per minute for HFNC/VMN compared with 138 beats per minute for facemask/JN administration. The authors believed that this reflected greater delivery of drug using HFNC/VMN.

\section{Vibrating mesh nebulisers in spontaneously breathing patients}

VMNs have been used to generate aerosolised drug delivery in many spontaneously breathing patients with respiratory difficulties.,39,90 The use of VMNs in this indication is supported by a range of bench studies that have demonstrated their advantages over JNs in terms of drug deposition.

Hickin et al. ${ }^{28}$ compared the dose and rate of drug delivery of a VMN with a standard $\mathrm{JN}$ fitted to a standard face mask in a breathing model simulating a normal patient and one having a COPD exacerbation. The VMN delivered salbutamol at a significantly higher rate than the JN $(257.9 \mu \mathrm{g} / \mathrm{min}$ versus $11.9 \mu \mathrm{g} / \mathrm{min})$ in simulated healthy patients $(p=0.008)$. In simulated COPD, these figures were $109.8 \mu \mathrm{g} / \mathrm{min}$ and $8.5 \mu \mathrm{g} / \mathrm{min}(\mathrm{p}=0.005)$ meaning that nebulisation time was almost halved. Furthermore, the VMN delivered nearly eight times the dose of salbutamol to the carina compared with the $\mathrm{JN}$; less than $1 \%$ of the original dose remained in the VMN reservoir (residual) compared with over $40 \%$ in the $\mathrm{JN}$ reservoir $(p<0.001)$.

Ari et al. conducted performance comparisons of JNs and VMNs using different interfaces in simulated spontaneously breathing adults and children..$^{90}$ Drug delivery was shown to be greater for the VMN than JN when using a mouthpiece (15.4\% versus $7.7 \%$ of nominal dose) or a valved mask (15.2\% versus $8.6 \%$ ), but was similar when using an aerosol mask (7.5\% versus 6.8\%).

Another model study investigated the risk of exposing carers and bystanders to aerosols as a result of leakage from facemasks and filtered mouthpieces used in combination with JNs. Simulated patient models showed that this risk is lower with VMNs than other aerosol devices due 
Figure 3: Scintigraphic images from two studies of lung deposition comparing a vibrating mesh nebuliser with a jet nebuliser in spontaneously breathing healthy subjects

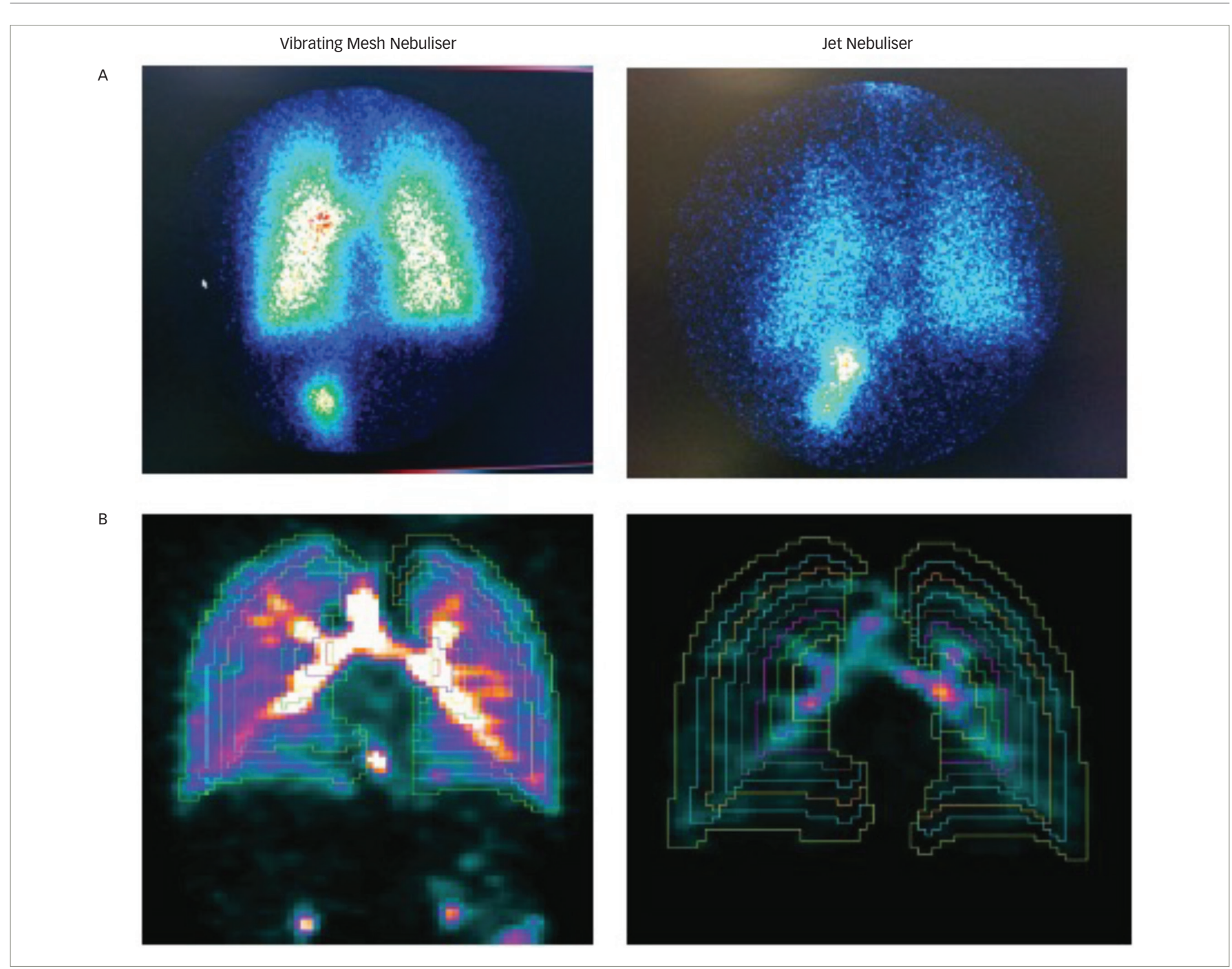

A: Reproduced with permission from Alcoforado et al., 2015.92 B: Reproduced with permission from Dugernier et al., 2017.93

to the fact they generate lower velocity aerosols. ${ }^{91}$ Such exposure risk is also decreased with a valved mask and mouthpiece.

In a scintigraphy study, spontaneously breathing healthy volunteer subjects ( $n=6)$ were treated with radio-aerosol (99mTC-DTPA) via a VMN (Aerogen Solo plus Aerogen Ultra) or a JN (NS, São Paulo, Brazil).92 The VMN achieved pulmonary deposition with four to six times greater efficiency compared with a JN (22.8\% versus $4.5 \%$ of dose delivered to the lungs; $\mathrm{p}=0.004)$. The $\mathrm{JN}$ also had a much greater residual volume resulting in lower drug delivery to the subject (Figure $3 A$ ). Further evidence of VMN efficiency comes from an imaging study with a crossover design that included six healthy male subjects. Single-photon emission computed tomography (SPECT-CT) was used to determine lung penetration of ${ }^{99 m}$ TC-DTPA that was administered via a VMN (Aerogen Ultra) or a JN (OptiMist Plus). ${ }^{93}$ Pulmonary aerosol deposition from SPECT-CT analysis was six times greater with the VMN compared with JN (34.1\% versus 5.2\%; $\mathrm{p}<0.001$ ) (Figure 3B). However, aerosol penetration expressed as the three-dimensional normalised ratio of the outer and inner regions of the lungs was similar between the $\mathrm{VMN}$ and JN.

VMNs have also shown efficacy in the administration of bronchodilators to spontaneously breathing patients with COPD. In a pilot study,
30 patients with an acute exacerbation of COPD were treated with a single bronchodilator dose $(2.5 \mathrm{mg}$ salbutamol/0.5 mg ipratropium bromide) using a VMN (Aerogen Ultra) or a JN (Hudson Micro Mist [Teleflex Medical Europe Limited, Athlone, Ireland])..$^{30}$ The VMN group demonstrated a significant improvement over $\mathrm{JN}$ in forced vital capacity $(p<0.05)$ and a greater volume response to bronchodilators with clinically significant increases in inspiratory capacity ( $>10 \%$ of predicted) and a clinically significant reduction in residual volume (>300 ml). There was also a significant improvement in the Borg breathlessness score from baseline with the VMN, with a trend to significance between the two nebulisers $(p=0.08)$. The authors concluded that since exacerbation recovery has been associated with increases in respirable lung volume, it is possible that greater bronchodilator delivery with VMNs may hasten exacerbation recovery, although this has yet to be explored.

Additional evidence showing the advantages of VMNs in spontaneously breathing patients came from a retrospective analysis of a large body of emergency department patient data $(n=1,594)$, which compared the efficacy of VMN ( $n=879$ ) (Aerogen Ultra) with JNS ( $n=715)$ (brand of $\mathrm{JN}$ not specified) in the administration of a bronchodilator (salbutamol) (Figure 4). ${ }^{31}$ Patients receiving JN treatment were 1.7 times more likely to be admitted to hospital than those receiving treatment with a VMN 
Figure 4: A: Admission rates; B: Discharge rates; C: Length of hospital stay in patients $(n=1,594)$ receiving bronchodilator treatments via vibrating mesh nebulisers or jet nebulisers

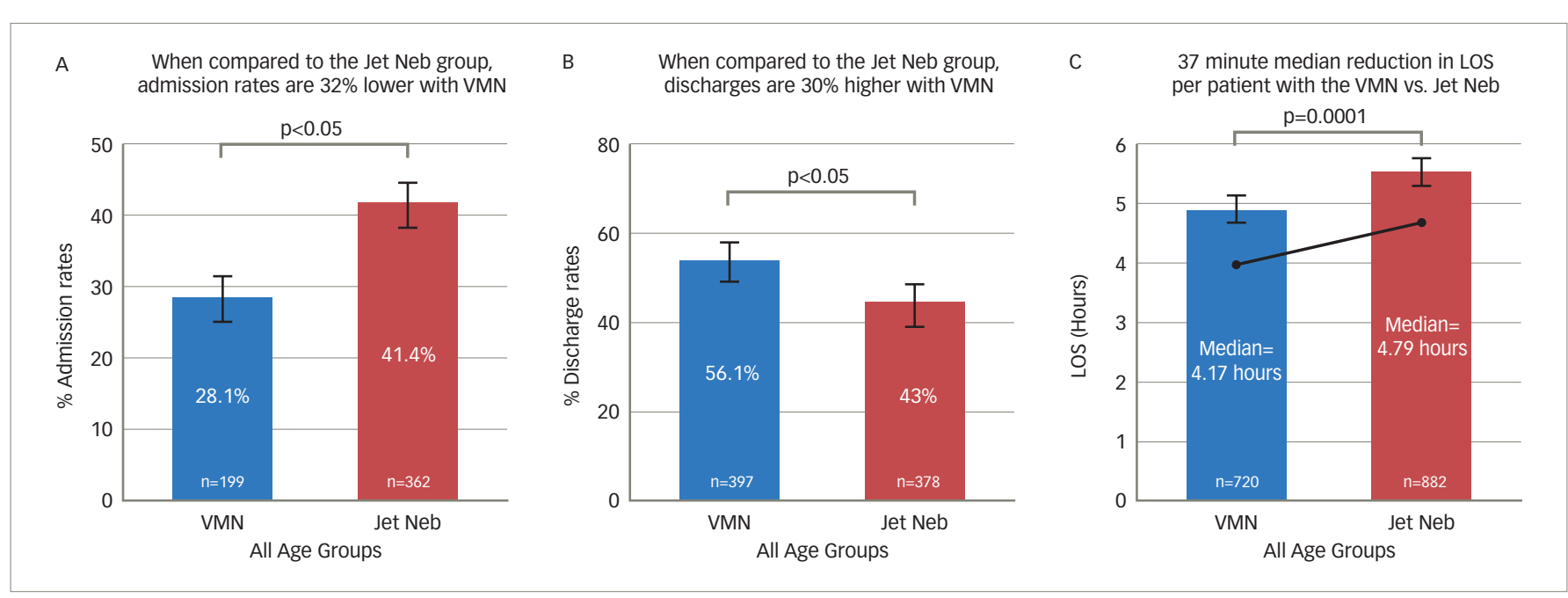

Jet Neb = jet nebuliser; LOS = length of stay; VMN = vibrating mesh nebuliser. Reproduced with permission from Dunne et al., $2016 .{ }^{31}$

Figure 5: Bronchodilator (salbutamol) doses required by patients $(n=1,594)$ receiving therapy via a vibrating mesh nebuliser or a jet nebuliser

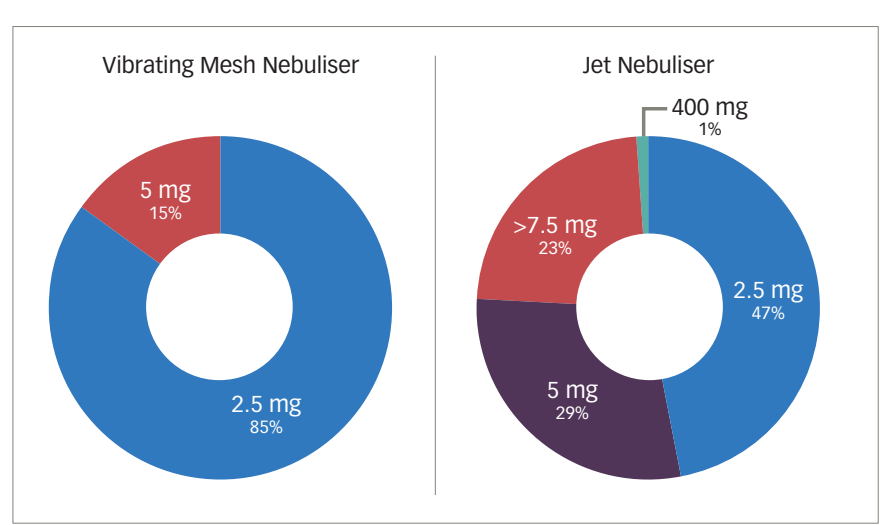

Salbutamol dose was significantly lower with vibrating mesh nebuliser than jet nebuliser; $p<0.001$. Reproduced with permission from Dunne et al., $2016 .{ }^{31}$

$(p<0.001)$. Patients receiving VMN treatment had significant reductions in median length of emergency department stay $(-13 \%)$ and were 1.3 times more likely to be discharged than those receiving JN treatment $(p<0.001){ }^{31}$ The VMN group used less total drug $(p<0.05)$ with a $75 \%$ reduction of maximum salbutamol dose administered (20 mg to $5 \mathrm{mg}$ ) (Figure 5). ${ }^{3}$

In patients with $\mathrm{CF}$, pulmonary infection is a persistent risk and cause of significant morbidity and mortality. ${ }^{7}$ MNs in handheld devices have been used in several pharmacokinetic studies to investigate antibiotic administration, particularly tobramycin, to treat $P$. aeruginosa and other Gram-negative bacterial infections in spontaneously breathing patients. One open-label, crossover study of 27 patients with CF and pulmonary $P$. aeruginosa infection investigated tobramycin (300 mg/4 ml) administrated via the PARI eFlow VMN nebuliser or the PARI LC Plus (a 'breath-enhanced' nebuliser for home use that uses a valve system to enhance delivery in a similar manner to the Aerogen Ultra). The VMNs produced similar pharmacokinetic profiles in plasma and sputum, but with shorter nebulisation times for the PARI eFlow device. ${ }^{94} \mathrm{~A}$ similar crossover study of 58 patients with CF and pulmonary $P$. aeruginosa infection compared $170 \mathrm{mg}$ tobramycin $/ 1.7 \mathrm{ml}$ via an
eFlow device with $300 \mathrm{mg}$ tobramycin/5 $\mathrm{ml}$ via a PARI LC Plus device. ${ }^{95}$ The $170 \mathrm{mg}$ tobramycin/1.7 $\mathrm{ml}$ treatment produced higher area under the curve (AUC) and maximum concentration $\left(C_{\max }\right)$ values but a lower systemic burden and shorter inhalation times, making it a favourable option for patients with CF. In a further crossover study of 29 patients with $\mathrm{CF}$ and chronic $P$. aeruginosa infection, tobramycin inhalation solution was administered via a VMN (PARI eFlow) once daily for 8 weeks, then twice daily for 8 weeks. ${ }^{96}$ The $\mathrm{AUC}_{0-90 \mathrm{~min}}$ ratio at 8 weeks and mean $\mathrm{FEV}_{1}$ did not differ markedly between the treatments and no nephrotoxic or audiological side effects were noted. This indicated that both onceand twice-daily tobramycin inhalation solution aerosol dosing achieves effective drug levels and both are tolerable. Overall, these studies indicate that VMN-nebulised antibiotics have considerable potential for the routine administration of antibiotics in CF.

Breath-enhanced/actuated nebulisers (BANs) are important frequently used aerosol generators in the treatment of spontaneously breathing patients. In a recent spontaneously breathing model study, a BAN (AeroEclipse ${ }^{\circledast}$ [Monaghan Medical Corporation, Plattsburgh, NY, US]) was compared with a VMN (Aerogen Solo plus Ultra). ${ }^{97}$ The VMN delivered two- to threefold greater drug dose than the BAN, with lower residual volume left in the VMN. Clinical investigations of BANs include a randomised controlled study by Sabato et al. ${ }^{98}$ In 149 spontaneously breathing paediatric patients with asthma in the emergency department, bronchodilator administration was compared using either a small volume standard JN (SVN), a large volume JN (LVN) or a BAN (AeroEclipse ${ }^{\circledR}$ ). Length of stay in the emergency department was not reduced; however, patients in the BAN group showed a greater improvement in clinical asthma score, respiratory rate and a significantly lower admission rate (38\% versus 57\%; $\mathrm{p}=0.03$ ). In an editorial review of this article, Ari and Fink identified a few confounding factors between the groups (SVN versus LVN versus BAN). ${ }^{98,99}$ The authors concluded that the method of delivering the bronchodilator could have impacted on the outcomes of the study.

\section{Discussion and future directions}

The evidence discussed above indicates that in both in vitro systems and patient studies investigating various ventilation modalities, VMNs showed greater efficiency in delivering drugs to lung tissues than JNS, pMDIs or UNS. This has the potential to improve patient outcomes; 
however, few randomised controlled trials studying patient outcomes have been published to date. ${ }^{3,12,47,100-2} \mathrm{VMN}$ administration is applicable to adult use but the efficiency and size of the aerosol particles also make it suitable for paediatric use where penetrating very small airways can be an issue. ${ }^{39,58,82,101,103}$ While much of the evidence justifying VMN aerosol administration comes from studies that use handheld or portable devices, there are indications that the devices have considerable potential for routine use in breathing circuits for patients in respiratory distress.

Compared to JNs, the key advantages of VMNs include: shorter treatment times; lower residual volumes $(<0.1 \mathrm{ml}$ for $3.0 \mathrm{ml}$ dose $)$ resulting in less drug wastage and higher amounts of drug being delivered to patients; and the possibility to nebulise small volumes of drug. VMNs can be used with most medications for inhalation. They do not heat or degrade medications so they are suitable for most solutions, suspensions, proteins and peptides. ${ }^{1,34}$ In mechanically ventilated patients, the extended time that VMNs can be left in place in the circuit reduces the need for manipulation, making it possible to refill medication without breaking the circuit. Ventilator parameters are therefore not disturbed and there is potentially lower risk of introducing infection. ${ }^{94,104}$ Clinical trials are required to confirm the patient outcomes related to these factors.

The recent pilot study by Cushen et al., ${ }^{30}$ suggested that utilising VMN to improve the delivery of bronchodilators to the airways of patients with acute exacerbations of COPD may improve lung volumes. However, this was only a single dose study and a multiple dose study would be needed to determine whether the improvements in lung volume and symptom score can result in shorter durations of acute exacerbations. This could be important in terms of shortening hospital admissions for patients with COPD and the consequent impact on healthcare costs, but also in potentially impacting the progressive lung damage caused by severe COPD exacerbations.

The recent retrospective analysis of 1,594 patients by Dunne et al. ${ }^{31}$ also suggested that in patients requiring nebulised bronchodilators it may be possible to reduce hospital admissions and length of stay in the emergency department. The latter might be due to more efficient drug delivery to the airways but could also be due to shorter treatment times. If these results can be confirmed in randomised, controlled clinical trials this would suggest substantial hospital savings from reduced hospital admissions and improved patient throughput in often overcrowded emergency departments. Several studies in the US ${ }^{49,68-70}$ have demonstrated notable savings in drug costs when using VMNs as opposed to MDIs in the intensive care setting but, as yet, there is little evidence available on cost savings from studies on other nebuliser types or from studies conducted in Europe or elsewhere where the costs of MDIs are much lower.

In addition to bronchodilators, VMNs are also used for the administration of a variety of other treatments. The nebulisation of antibiotics for difficult to treat respiratory infections such as VAP or community-acquired pneumonia, ${ }^{71,72,105}$ or chronic and acute pulmonary infections in $\mathrm{CF}^{7,101}$ has increased substantially over recent years. This is driven by the possibility of achieving higher antibiotic concentrations in the infected tissue while keeping systemic blood levels low and potentially improving the therapeutic index. This is important especially when some of the antibiotics required to treat multidrug resistant infections have serious systemic toxicity, but also given the concerns around antibiotic resistance and the need to control the doses of these powerful drugs. ${ }^{7,106}$

There are many publications outlining the use of VMNs for delivery of heparin for pulmonary inflammation in ventilated patients, ${ }^{32}$ antifungals for invasive aspergillosis, ${ }^{107-109}$ furosemide for COPD exacerbations, surfactant for neonates, prostacyclins for pulmonary hypertension, bronchopulmonary dysplasia and breathlessness in lung cancer, ${ }^{33,10,111}$ and the administration of insulin to patients with diabetes. ${ }^{112-114}$ However, many of these drugs are not approved for inhalation or are not specifically approved for inhalation with a VMN and are off label. Further clinical studies are needed to better support the use of VMNs in this wider range of indications.

A notable development in VMN systems in recent years has been the appearance of the so-called 'smart nebulisers' such as the I-neb Adaptive Aerosol Delivery (AAD) System (Philips Healthcare Limited, Guildford, Surrey, UK). ${ }^{115-117}$ These systems have the potential to improve nebuliser efficiency by adapting delivery in response to the patient's breathing pattern. Smart nebulisers also have internet connectivity providing feedback to the patient and healthcare professionals via a smart phone for monitoring adherence, patient condition and device performance. The high cost of the I-neb AAD System is a potential downside. It is only for use in spontaneously breathing patients and can't be used during mechanical ventilation. ${ }^{116}$

Respiratory conditions including COPD, asthma and CF impose increasingly serious health burdens on worldwide populations and VMN technology has the potential to improve aerosol treatments for these diseases. Bench models and imaging data confirm the high efficiency of VMNs to deliver drug to the lungs and airways across all ventilation modalities. Early clinical studies, especially in spontaneous breathing patients, may suggest that increased bronchodilator delivery to the airways and lungs could improve clinical outcomes in terms of shortening treatment times and potentially reducing hospital admissions and duration of exacerbations, but much larger randomised studies are needed to confirm this. There are many ongoing antibiotic delivery studies which will report in the coming years. Delivering more drug to the airways and lungs, therefore, has the potential to more rapidly and cost-effectively resolve acute exacerbations of respiratory disease than is currently possible and may positively impact outcomes in an increasing population of patients worldwide. $\square$
1. Ari A, Fink JB. Aerosol drug delivery during mechanical ventilation: devices, selection, delivery technique, and evaluation of clinical response to therapy. Clin Pulm Med. 2015;22:79-86.

2. Bonini M, Usmani OS. The importance of inhaler devices in the treatment of COPD. COPD Research and Practice. 2015;1:9.

3. Ehrmann S, Roche-Campo F, Bodet-Contentin L, et al. Aerosol therapy in inonive observation of 2808 critically ill patients. Intensive Care Med. 2016:42:192-201.

Molimard M, Colthorpe P. Inhaler devices for chronic obstructive pulmonary disease: insights from patients an obstructive pulmonary disease: insights from patients and
healthcare practitioners. J Aerosol Med Pulm Drug Deliv. healthcare practition
5. Virchow JC, Crompton GK, Dal Negro R, et al. Importance of inhaler devices in the management of airway disease. Respir Med. 2008;102:10-9.

6. Baravalle-Einaudi M, Dufeu N, Dupont C, et al. Vibrating-mesh nebulizer maintenance by CF patients: results from a French survey. Pulm Pharmacol Ther. 2017;44:57-60.

7. Maselli DJ, Keyt H, Restrepo MI. Inhaled antibiotic therapy in chronic respiratory diseases. Int J Mol Sci. 2017:18:1062.

8. Dhanani J, Fraser JF, Chan HK, et al. Fundamentals of aerosol therapy in critical care. Crit Care. 2016;20:269.

9. Labiris NR, Dolovich MB. Pulmonary drug delivery. Part I: physiological factors affecting therapeutic effectiveness of aerosolized medications. Br J Clin Pharmacol. 2003;56:588-99. 10. Ari A, Fink JB. Factors affecting bronchodilator delivery in mechanically ventilated adults. Nurs Crit Care. 2010;15:192-203. 11. Bhashyam AR, Wolf MT, Marcinkowski AL, et al. Aerosol delivery through nasal cannulas: an in vitro study. J Aerosol Med Pulm Drug Deliv, 2008;21:181-8.

12. Bohr A, Beck-Broichsitter M. Generation of tailored aerosols for inhalative drug delivery employing recent vibrating-mesh nebulizer systems. Ther Deliv. 2015;6:621-36.

13. MacIntyre NR, Silver M, Miller CW, et al. Aerosol delivery in intubated, mechanically ventilated patients. Crit Care Med, 1985:13:81-4.

14. Arpinelli $F$, Carone M, Riccardo $G$, et al. Health-related quality of life measurement in asthma and chronic obstructive pulmonary disease: review of the 2009-2014 literature. Multidiscip Respir Med. 2015;11:5. 
15. Collar JM. Asthma and COPD in Spain: quality of life and health consumption resources. Value Health. 2014;17:A601.

16. Jones GL. Quality of life changes over time in patients with chronic obstructive pulmonary disease. Curr Opin Pulm Med. 2016:22:125-9.

17. Wang $Y$, Ghoshal $A G$, Bin Abdul Muttalif $A R$, et al. Quality of life and economic burden of respiratory disease in Asia-Pacific burden of respiratory diseases study. Value Health Reg Issues. 2016;9:72-7.

18. Dang-Tan T, Ismaila A, Zhang S, et al. Clinical, humanistic, and economic burden of chronic obstructive pulmonary disease (COPD) in Canada: a systematic review. BMC Res Notes, 2015;8:464

19. Ehteshami-Afshar S, FitzGerald JM, Doyle-Waters MM, et al. The global economic burden of asthma and chronic obstructive pulmonary disease. Int J Tuberc Lung Dis. 2016;20:11-23.

20. Kim J, Lee TJ, Kim S, et al. The economic burden of chronic obstructive pulmonary disease from 2004 to 2013. J Med Econ. 2016;19:103-10.

21. Lewis A, Torvinen S, Dekhuiizen PN, et al. The economic burden of asthma and chronic obstructive pulmonary disease and the impact of poor inhalation technique with commonly prescribed dry powder inhalers in three European countries. BMC Healt Serv Res. 2016;16:251

22. LoftuS PA, Wise SK. Epidemiology and economic burden of asthma. Int Forum Allergy Rhinol. 2015;5:S7-10

23. World Health Organization (WHO). Chronic respiratory diseases - burden of COPD, 2017. Available at: www.who.int/respiratory/ copd/burden/en/ (accessed 4 January 2018).

24. World Health Organisation (WHO). 10 Facts on asthma, 2011 Available at: www.who.int/features/factfiles/asthma/en/ (accessed 4 January 2018).

25. Global Asthma Network. Global asthma report 2014, 2014. Available at: www.globalasthmareport.org/priority/priority.php (accessed 4 January 2018)

26. Clay MM, Clarke SW. Wastage of drug from nebulisers: a review. IR SOC Med 1987:80:38-9.

27. Coates AL, Denk O, Leung K, et al. Higher tobramycin concentration and vibrating mesh technology can shorten antibiotic treatment time in cystic fibrosis. Pediatr Pulmonol. 2011;46:401-8.

28. Hickin S, MacLoughlin R, Sweeney L, et al. Comparison of mesh nebuliser versus jet nebuliser in simulated adults with chronic obstructive pulmonary disease. Presented at: College of Emergency Medicine Clinical Excellence Conference, Exeter UK, 9-11 September 2014. Available at: www.researchgate. net/publication/275967492_Comparison_of_mesh_nebuliser versus jet nebuliser_in_simulated_adults_with_chronic obstructive_pulmonary_disease (accessed 4 January 2018).

29. Michotte JB, Jossen E, Roeseler J, et al. In vitro comparison of five nebulizers during noninvasive ventilation: analysis of inhaled and lost doses, J Aerosol Med Pulm Drug Deliv. 2014;27:430-40

30. Cushen B, Alsaid A, Abdulkareem A, et al. P292 A pilot study to assess bronchodilator response during an acute exacerbation of COPD using a vibrating mesh nebuliser versus jet nebulise for bronchodilator delivery. Thorax. 2016;71:A251.

Dunne RB, Shortt S. Comparison of bronchodilat administration with vibrating mesh nebulizer and standard jet nebulizer in the emergency department. Am I Emerg Med. 2017. doi: 10.1016/i.ajem.2017.10.067 [Epub ahead of print].

32. Dixon B, Schultz MJ, Smith R, et al. Nebulized heparin is associated with fewer days of mechanical ventilation in critically ill patients: a randomized controlled trial. Crit Care. 2010;14:R180.

33. Sheikh Motahar Vahedi $\mathrm{H}$, Mahshidfar B, Rabiee $\mathrm{H}$, et a The adjunctive effect of nebulized furosemide in COPD exacerbation: a randomized controlled clinical trial. Respir Care. 2013;58:1873-7.

34. Dhand R. Nebulizers that use a vibrating mesh or plate with multiple apertures to generate aerosol. Respir Care. 2002;47:1406-18.

35. Sagalla RB, Smaldone GC. Capturing the efficiency of vibrating mesh nebulizers: minimizing upper airway deposition. J Aeroso Med Pulm Drug Deliv. 2014;27:341-8.

36. Vecellio L. The mesh nebuliser: a recent technical innovation for aerosol delivery. Breathe. 2006;2:253-60.

37. Waldrep IC, Dhand R. Advanced nebulizer designs employing vibrating mesh/aperture plate technologies for aerosol generation. Curr Drug Deliv. 2008:5:114-9.

38. Dugernier $\mathrm{J}$, Hesse M, Jumetz $\mathrm{T}$, et al. Aerosol delivery with two nebulizers through high-flow nasal cannula: a randomized cross-over single-photon emission computed tomographycomputed tomography study. J Aerosol Med Pulm Drug Deliv. 2017;30:349-58

39. Dugernier J, Reychler G, Wittebole X, et al. Aerosol delivery with two ventilation modes during mechanical ventilation: a randomized study. Ann Intensive Care. 2016;6:73

40. Moustafa IOF, ElHansy MHE, Al Hallag M, et al. Clinical outcome associated with the use of different inhalation method with an without humidification in asthmatic mechanically ventilated patients. Pulm Pharmacol Ther. 2017:45:40-6.

41. Réminiac F, Gissot V, Vecellio $L$, et al. Nebulization during nasal high flow therapy: interim results of a randomized clinical trial. Presented at: 1st Congress of the International Society for Aerosols in Medicine, Santa Fe, New Mexico, USA, 3-7 June 2017. Poster P181.

42. Omron Healthcare, Inc. Omron ${ }^{\oplus}$ Portable MicroAir Nebulizer Model: NE-U22V, 2017. Available at: https://omronhealthcare. com/products/microair-nebulizer-neu22v/ (accessed 4 January

3. PARI. PARI Products - eFlow rapid nebuliser system, 2017 Available at: www.pari.com/uk-en/products/lower-airways-1/ flow-rapid-nebuliser-system-1/ (accessed 4 January 2018). 4. Aerogen Pharma. Aerogen ${ }^{\circledast}$ Solo, 2016. Available at: www. aerogen.com/aerogen-solo-3/ (accessed 4 January 2018).

45. Aerogen Pharma. Aerogen $\otimes$ Ultra 2016. Available at: wmw. aerogen.com/products/aerogen-ultra/ (accessed 4 Januan 2018).

46. Ari A, Fink JB, Dhand R. Inhalation therapy in patients receiving mechanical ventilation: an update. J Aerosol Med Pulm Drug Deliv. 2012;25:319-32.

4. Martin AR, Finlay WH. Nebulizers for drug delivery to the lungs. Expert Opin Drug Deliv. 2015;12:889-900.

4. Ari A. Aerosol therapy in pulmonary critical care. Respir Care. 2015;60:858-79

49. Streepy K, Dawson AM, Grigonis AM, et al. Conversion from metered dose inhalers to a vibrating mesh nebulizer in long term acute care hospitals: cost effectiveness and respiratory staff perception. Presented at: American Society of Health-System Pharmacists Summer Meeting \& Exhibition, Minneapolis, MN US, 1-5 June 2013.

50. Ari A. Jet, ultrasonic, and mesh nebulizers: an evaluation of nebulizers for better clinical outcomes. Eurasian I Pulmonol. 2014;16:1-7.

51. Ehrmann S, Roche-Campo F, Sferrazza Papa GF, et al. Aerosol therapy during mechanical ventilation: an international survey. intensive Care Med. 2013;39:1048-56.

52. Sidler-Moix AL, Di Paolo ER, Dolci U, et al. Physicochemical aspects and efficiency of albuterol nebulization: comparison of three aerosol types in an in vitro pediatric model. Respir Care. 2015;60:38-46.

53. Skaria S, Smaldone GC. Omron NE U22: comparison between vibrating mesh and jet nebulizer. J Aerosol Med Pulm Drug Deliv. 2010;23:173-80.

54. Ahmed SM, Athar M. Mechanical ventilation in patients with chronic obstructive pulmonary disease and bronchial asthma. indian J Anaesth. 2015:59:589-98.

55. Rose L. Management of critically ill patients receiving noninvasive and invasive mechanical ventilation in the emergency department. Open Access Emerg Med. 2012;4:5-15.

56. Suau SJ, DeBlieux PM. Management of acute exacerbation of asthma and chronic obstructive pulmonary disease in the emergency department. Emerg Med Clin North Am. 2016;34:15-37.

57. Guerin C, Fassier T, Bayle F, et al. Inhaled bronchodilator administration during mechanical ventilation: how to optimize it, and for which clinical benefit? J Aerosol Med Pulm Drug Deliv. 2008;21:85-96

58. Macintyre NR, Nava S, Diblasi RM, et al. Respiratory care year in review 2010: part 2. Invasive mechanical ventilation, oninvasive ventilation, pediatric mechanical ventilation, erosol therapy. Respir Care 2011:56:667-80.

59. Michalopoulos A Metaxas El, Falagas ME. Aerosol delivery of antimicrobial agents during mechanical ventilation: current practice and perspectives. Curr Drug Deliv. 2011;8:208-12.

6. Berlinski A, Kumaran S. Particle size characterization of nebulized albuterol delivered by a vibrating mesh nebulizer through pediatric endotracheal tubes. Am J Respir Crit Care Med. 2017;195:A2812

61. Berlinski A, Willis JR. Albuterol delivery by 4 different nebulizers placed in 4 different positions in a pediatric ventilator in vitro model. Respir Care. 2013;58:1124-33.

62. Berlinski A, Willis JR. Effect of tidal volume and nebulizer type and position on albuterol delivery in a pediatric model of mechanical ventilation. Respir Care. 2015:60:1424-30.

63. Fang TP, Lin HL, Chiu SH, et al. Aerosol delivery using jet nebulizer and vibrating mesh nebulizer during high frequency scillatory ventilation: an in vitro comparison. J Aerosol Med Pulm Drug Deliv 2016:29:447-53.

64. Ari A, Atalay OT, Harwood R, et al. Influence of nebulizer type, position, and bias flow on aerosol drug delivery in simulated pediatric and adult lung models during mechanical ventilation. Respir Care. 2010;55:845-51.

65. Dubus JC, Vecellio L, De Monte M, et al. Aerosol deposition in neonatal ventilation. Pediatr Res. 2005;58:10-4.

66. Ramsi MA, Henry M, Milla CE, et al. Inhaled $\beta 2$-agonist therapy increases functional residual capacity in mechanically ventilated children with respiratory failure. Pediatr Crit Care Med. 2015;16:e189-93.

67. Dhand R. Inhalation therapy with metered-dose inhalers and dry powder inhalers in mechanically ventilated patients. Respir Care. 2005:50:1331-45.

68. MCDaniel C Glynn B, Gudowskis, et al Conversion of pressurized metered-dose inhaler to vibrating mesh nebulizer administered medications, Presented at: Society of Critical Care Medicine 42nd Critical Care Congress, San Juan, Puerto Rico, 19-23 January 2013. Poster 404

69. Loborec SM, Johnson SE, Keating EA. Financial effect of converting ipratropium-albuterol therapy from inhalers to nebulizer treatments at an academic health system. Am J Health Syst Pharm. 2016;73:121-5.

70. Blake G, Yaklic J, Cobb J. Transition from ipratropium/albuterol inhaler to nebulizer on quality and cost savings in ventilated patients. Presented at: American Society of Health-System Pharmacists Summer Meeting, Minneapolis, MN, US, 1-5 June 2013.

71. Lu Q, Luo R, Bodin L, et al. Efficacy of high-dose nebulize colistin in ventilator-associated pneumonia caused by multidrug-resistant Pseudomonas aeruginosa and Acinetobacter baumannii. Anesthesiology 2012:117:1335-47.

72. Abdellatif S, Trifi A, Daly F, et al. Efficacy and toxicity of aerosolised colistin in ventilator-associated pneumonia: a prospective, randomised trial. Ann Intensive Care. 2016;6:26.

73. Hess DR. Noninvasive positive-pressure ventilation and

ventilator-associated pneumonia. Respir Care. 2005:50:924-31.

74. Keyt $\mathrm{H}$, Faverio $\mathrm{P}$. Restrepo Ml. Prevention of ventilatorassociated pneumonia in the intensive care unit: a review of the clinically relevant recent advancements. Indian I Med Res. 2014:139:814-21.

75. Lindenauer PK, Stefan MS, Shieh MS, et al. Outcomes associated with invasive and noninvasive ventilation among patients hospitalized with exacerbations of chronic obstructive pulmonary disease. JAMA Intern Med. 2014;174:1982-93.

6. Crimi C, Noto A, Princi P, et al. Domiciliary non-invasive ventilation in COPD: an international survey of indications and practices. COPD. 2016;13:483-90

77. Osadnik CR, Tee VS, Carson-Chahhoud KV, et al. Non-invasive ventilation for the management of acute hypercapnic respiratory failure due to exacerbation of chronic obstructive pulmonary disease. Cochrane Database Syst Rev. 2017;7:CD004104.

78. Abdelrahim ME, Plant P, Chrystyn $\mathrm{H}$. In-vitro characterisation of the nebulised dose during non-invasive ventilation. $J$ Pharm Pharmacol. 2010;62:966-72.

79. MCPeck M. Improved aerosol drug delivery with an electronic mesh nebulizer during non-invasive ventilation. Respir Care. 2012;57:1705

80. Velasco J, Berlinski A. Aerosol delivery in a pediatric mode of non-invasive ventilation. Am J Respir Crit Care Med. 2016;193:A2201

81. Dhand R, Wang H, McCormack MT, et al. Comparison of aeroso delivery during simulated adult noninvasive positive pressure ventilation: nebulizer versus pressurized metered-dose inhaler. Am J Respir Crit Care Med. 2016;193:A5343.

82. Galindo-Filho VC, Ramos ME, Rattes CS, et al. Radioaerosol pulmonary deposition using mesh and jet nebulizers during noninvasive ventilation in healthy subjects. Respir Care. 2015;60:1238-46.

83. Ari A, Harwood R, Sheard M, et al. In vitro comparison of heliox and oxygen in aerosol delivery using pediatric high flow nasal cannula Pediatr Pulmonol. 2011:46:795-801.

84. Pacocha D, Thayer T, Dailey PA, et al. Comparison of aerosol delivery with three high flow nasal cannula types and sizes. Presented at American Association for Respiratory Care Congress, San Antonio, TX, US, 15-18 October 2016.

85. Reminiac F, Vecellio L, Heuze-Vourc'h $\mathrm{N}$, et al. Aerosol therapy n adults receiving high flow nasal cannula oxygen therapy. $J$ Aerosol Med Pulm Drug Deliv. 2016;29:134-41.

86. Sunbul FS, Fink JB, Harwood R, et al. Comparison of HFNC, bubble CPAP and SiPAP on aerosol delivery in neonates: an in-vitro study. Pediatr Pulmonol. 2015;50:1099-106.

87. Alcoforado L, del Melo Barcelar J, Brandio SCS, et al. Comparison of aerosol deposition with heated and unheated high flow nasal cannula (HFNC) in healthy adults. Am J Respir Crit Care Med. 2016:193:A5320.

88. Morgan SE, Mosakowski S, Solano P, et al. High-flow nasal cannula and aerosolized $\beta$ agonists for rescue therapy in children with bronchiolitis: a case series. Respir Care. 2015;60:e161-5

89. Alhamad BR, Fink JB, Harwood RJ, et al. Effect of aerosol devices and administration techniques on drug delivery in a simulated spontaneously breathing pediatric tracheostomy model. Respir Care. 2015;60:1026-32.

90. Ari A, de Andrade AD, Sheard M, et al. Performance comparisons of jet and mesh nebulizers using different interfaces in simulated spontaneously breathing adults and children. J Aerosol Med Pulm Drug Deliv. 2015;28:281-9.

91. O'Sullivan A, McGrath J. Byrne M, et al. Assessment of exhaled aerosol emissions using two prevalent nebuliser technologies in clinical use today Presented at: Drug Delivery to the Lungs Conference (DDL27), Edinburgh, UK, 7-9 December 2016.

92. Alcoforado L de Melo Barcelar J, Galindo VC, et al. Analysis of deposition radioaerosol nebulizers membrane in healthy subjects. Presented at: International Society for Aerosols in Medicine (ISAM), Munich, Germany, 31 May-3 June 2015.

93. Dugernier J, Hesse M, Vanbever R, et al. SPECT-CT comparison of lung deposition using a system combining a vibrating-mesh nebulizer with a valved holding chamber and a conventional jet nebulizer: a randomized cross-over study. Pharm Res. 2017;34:290-300

94. Govoni M, Poli G, Acerbi D, et al. Pharmacokinetic and tolerability profiles of tobramycin nebuliser solution $300 \mathrm{mg} / 4 \mathrm{ml}$ administered by PARI eFlow ${ }^{\circledR}$ rapid and PARI LC Plus ${ }^{\oplus}$ nebulisers in cystic fibrosis patients. Pulm Pharmacol Ther. 2013;26:249-55.

95. Sands D, Sapiejka E, Gaszczyk G, et al. Comparison of two tobramycin nebuliser solutions: pharmacokinetic, efficacy and safety profiles of T100 and TNS. J Cyst Fibros. 2014;13:653-60.

6. van Koningsbruggen-Rietschel S, Heuer HE, Merkel N, et al. Pharmacokinetics and safety of an 8 week continuous treatment with once-daily versus twice-daily inhalation of 
102. Tashkin DP. A review of nebulized drug delivery in COPD. Int Chron Obstruct Pulmon Dis. 2016;11:2585-96.

103. Dailey P. Tina T, Santos J, et al. Performance improvement plan for pediatric patients in respiratory distress: clinical experience. Respiratory Therapy. 2015;10:27-9.

104. Dubosky MN, Lamorena EK, Jones C, et al. Clinical outcomes associated with vibrating mesh and jet nebulizers during mechanical ventilation in the acute care setting: a randomized controlled trial. Respir Care. 2016;61:OF22.

105. Pedersen KM, Handlos VN, Heslet L, et al. Factors influencing the in vitro deposition of tobramycin aerosol: a comparison of an ultrasonic nebulizer and a high-frequency vibrating mesh nebulizer. J Aerosol Med. 2006;19:175-83.

106. Ehrmann $S$, Chastre J, Diot P, et al. Nebulized antibiotics in mechanically ventilated patients: a challenge for translationa research from technology to clinical care. Ann Intensive Care. $2017 \cdot 7 \cdot 78$

107. Godet C, Cateau E, Rammaert B, et al. Nebulized liposomal amphotericin B for treatment of pulmonary infection caused by Hormographiella aspergillata: case report and literature review. Mycopathologia, 2017;182:709-13.

108. Karthaus M, Buchheidt D. Invasive aspergillosis: new insights into disease, diagnostic and treatment Curr Pharm Des.
int 2013:19:3569-94.

109. Kontoyiannis DP, Patterson TF. Diagnosis and treatment of invasive fungal infections in the cancer patient: recent progress and ongoing questions. Clin Infect Dis. 2014;59 Suppl. 5:S356-9.

110. Sahni J, Phelps SJ. Nebulized furosemide in the treatment of bronchopulmonary dysplasia in preterm infants. $J$ Pediatr Pharmacol Ther. 2011;16:14-22.

111. Wilcock A, Walton A, Manderson C, et al. Randomised, placebo controlled trial of nebulised furosemide for breathlessness in patients with cancer. Thorax. 2008;63:872-5.

112. Becquemin $\mathrm{MH}$, Chaumuzeau JP. Inhaled insulin: a model for pulmonary systemic absorption? Rev Mal Respir. 2010;27:e54-65.
113. Perera AD, Kapitza C, Nosek L, et al. Absorption and metabolic effect of inhaled insulin: intrapatient variability after inhalation via the Aerodose insulin inhaler in patients with type 2 diabetes. Diabetes Care. 2002;25:2276-81.

114. Zarogoulidis P, Papanas N, Kouliatsis G, et al. Inhaled insulin: too soon to be forgotten? J Aerosol Med Pulm Drug Deliv. 2011;24:213-23.

115. Denyer J, Dyche T. The Adaptive Aerosol Delivery (AAD) technology: past, present, and future. J Aerosol Med Pulm Drug Deliv. 2010;23 Suppl. 1:S1-10.

116. Dhand R. Intelligent nebulizers in the age of the internet: the I-neb Adaptive Aerosol Delivery (AAD) system. J Aerosol Med Pulm Drug Deliv. 2010;23 Suppl. 1:iii- $v$.

117. Geller DE, Kesser KC. The I-neb Adaptive Aerosol Delivery system enhances delivery of alpha1-antitrypsin with controlled inhalation. J Aerosol Med Pulm Drug Deliv. 2010;23 Suppl. 1:S55-9. 